\title{
Confiança e complexidade social em Niklas Luhmann
}

\author{
Trust and social complexity in Niklas Luhmann
}

\section{Rodrigo Mota}

Resumo O problema da complexidade social era considerado por Niklas Luhmann uma questão fundamental da sociologia. Sua Teoria dos Sistemas Sociais visa, no fundo, explicar de que forma lida a humanidade com esse problema que cresce desde o advento da modernidade. Nesse contexto, a confiança se mostra como um importante mecanismo de redução de complexidade. Em um mundo onde se multiplicam as escolhas, faz-se necessário o uso de um mecanismo que nos ajude a pré-selecionar tais escolhas e alivie-nos da quantidade necessária de informações para que possamos agir. A confiança faz com que, mesmo sem estarmos plenamente informados sobre uma situação ou pessoa, possamos agir baseando-nos no que já conhecemos, em nossa própria história, no passado que já é complexidade reduzida. Este artigo pretende expor e problematizar o estudo de Luhmann sobre esse tema, relacionando-o com o pioneirismo de Georg Simmel e a algumas contribuições posteriores.

Palavras-chave Confiança; Complexidade; Luhmann; Simmel; Teoria dos Sistemas Sociais.

Abstract The problem of social complexity was considered by Niklas Luhmann as the fundamental problem of sociology. His Theory of Social Systems aims in explaining in what way mankind deals with this problem that grows since the arrival of modernity. In this context, trust shows itself as an important mechanism for the reduction of complexity. In a world where choices multiply, it becomes necessary the use of a mechanism that help us to pre-select those choices and relieves us on the necessary amount of information to act. Trust allows us to act, even when we don't have enough information about a situation or a person, based on what we already know, our own history, past that already is complexity reduced. This article intends to expose Luhmann's study on this matter, relating it to Georg Simmel's pioneer approach and later contributions.

Keywords Trust; Complexity; Luhmann; Simmel; Social Systems Theory.

a Doutorando em Ciências Sociais e mestre em Filosofia pela Universidade Federal de Pernambuco (UFPE). Possui graduação em Ciências Sociais pela Universidade Federal de Pernambuco e Especialização em Filosofia Contemporânea pela Universidade Católica de Pernambuco. 


\section{INTRODUÇÃO}

A teoria social produzida por Niklas Luhmann (1927-1998) é monumental, não apenas pela tentativa de estabelecer um novo paradigma nas ciências sociais, mas também pela sua dimensão física, já que Luhmann produziu nos seus trinta anos de atividade como pesquisador aproximadamente 60 obras, uma média de dois livros por ano. Além dessa grandeza numérica existe a singular interdisciplinaridade da sua Systemtheorie. Enquanto outras teorias, inclusive a do seu mentor Talcott Parsons, buscavam esta interdisciplinaridade em disciplinas vizinhas, como a psicologia e a economia, Luhmann foi da biologia à cibernética, sempre preocupado com inovações conceituais que pudessem clarear o entendimento dos fenômenos sociais. Nessa imensa obra científica, Luhmann escreveu sobre diversos temas relevantes para a sociologia, dentro do contexto da sua Teoria dos Sistemas Sociais Autopoiéticos. A partir de 1984 ele inicia, com o livro Soziale Systeme (Sistemas sociais), uma série de obras sobre os mais diversos sub-sistemas sociais (Die Wirtschaft der Gesellschaft [A economia da sociedade], Die Wissenschaft der Gesellschaft [A ciência da sociedade], Das Recht der Gesellschaft [O direito da sociedade], Die Kunst der Gesellschaft [A arte da sociedade]), até culminar no maior de todos os sistemas sociais, a própria sociedade, em Die Gesellschaft der Gesellschaft (A sociedade da sociedade).

A complexidade da teoria de Luhmann só perde para a complexidade da própria sociedade, característica que é "exatamente o que constitui sua sensibilidade empírica para com a inter-relação entre organizações e sociedade na sociedade hiper-complexa de hoje" (Holmström, 2007, p. 255, em livre tradução). Uma análise detalhada desta teoria exige pelo menos um livro extenso, como os que Luhmann costumava escrever. Como neste trabalho meu foco será dirigido às suas ideias sobre a confiança, me limitarei aos elementos da sociologia luhmanniana relevantes a este tema. Dado que o livro sobre esse assunto foi publicado pela primeira vez em 1968, ou seja, no início da carreira de Luhmann como sociólogo, se percebe que muitos elementos relevantes em obras posteriores ou não estavam presentes ou não estavam devidamente maduros, como, por exemplo, a relação entre a estrutura social e a semântica, e a ausência de uma definição mais clara sobre o que viria a ser definido por ele como meios de comunicação simbolicamente generalizados (Symbolisch generalisiert Kommunukations medien), conceito este que se observa bem desenvolvido na sua obra sobre o amor, de 1982, Liebe als Passion (Amor como paixão), além da própria ideia de Autopoiesis, fundamental na Systemtheorie de Luhmann, mas que não se encontra presente nesta obra sobre a confiança. A ausência de algum destes conceitos deve ser justificada considerando os limites a 
que está sujeito este trabalho, fazendo-se necessária uma maior ênfase e espaço ao "problema dos problemas", que se relaciona diretamente com a confiança: a complexidade.

\section{A SOCIOLOGIA COMO TEORIA DOS SISTEMAS SOCIAIS E A COMPLEXIDADE}

Na década de 1960, Niklas Luhmann estudou uma temporada em Harvard onde conheceu o sociólogo Talcott Parsons e sua teoria estrutural-funcional. Foi sob a influência de Parsons que Luhmann começou a desenvolver a sua própria teoria social, numa espécie de "reforma" da teoria parsoniana. Dentro desta reforma a principal crítica dizia respeito à falta de mobilidade estrutural da sociedade nesta teoria, posto que o estrutural-funcionalismo "pré-ordena o conceito de estrutura ao conceito de função" (Luhmann, 2005, p. 73). Dessa forma, "a teoria estrutural-funcional priva-se [...] da possibilidade de problematizar estruturas e de indagar em geral o sentido da formação estrutural, de acordo com o sentido da formação sistêmica" (Luhmann, 2005, p. 74). Por isso, Luhmann propõe uma teoria funcional-estrutural, na qual o ponto de referência seja a diferença entre o ambiente (Umwelt) e o sistema, que no caso específico da sociologia é o sistema social. $^{1}$

A identidade do sistema é formada por essa relação dentro/fora. $\mathrm{O}$ ambiente "não pode apreender-se como sistema, porque não tem nenhum 'fora', frente ao qual ele se delimite" (Luhmann, 2005, p. 76). Essa separação, fundamento da teoria de Luhmann, não era possível enquanto se definia o sistema como um todo constando de partes sem referência a um ambiente. Este novo rumo foi oferecido pela fenomenologia de Edmund Husserl (enorme influência no pensamento luhmanniano), "sobretudo graças à distinção entre identidade significativa e intentável e horizonte de toda a vivência, que tornou possível definir o mundo como horizonte universal" (Luhmann, 2005, p. 76). Pela ausência de um "fora”, o ambiente não encontra sua existência em si ameaçada; diferentemente dos sistemas, a existência deste não é problemática. Neste caso, "o mundo torna-se problema”, não sob o ponto de vista do seu ser, mas sob o ponto de vista de sua complexidade. Por complexidade deve aqui se entender "a totalidade dos acontecimentos possíveis. [...] O conceito de complexidade designa sempre uma relação entre sistema e mundo, nunca um estado do ser" (Luhmann, 2005, p. 77).

1 "Por sistema social deve aqui entender-se uma conexão de sentido das acções sociais, que se referem umas às outras e se podem delimitar de um ambiente de acções não pertinentes" (LuHMann, 2005, p. 75). 
Um dos principais distanciamentos da teoria dos sistemas de Luhmann em relação à teoria estrutural-funcionalista de Parsons, para melhor posicioná-la num contexto mais amplo da teoria social, é em relação à unidade elementar da sociologia. Para Parsons, essa unidade era a ação social; para Luhmann, a comunicação² .

\begin{abstract}
Para a teoria dos sistemas autopoiéticos, apenas a comunicação é uma séria candidata à posição de unidade elementar do processo auto-referencial básico dos sistemas sociais. Apenas a comunicação é necessariamente e inerentemente social; a ação não é. Mais ainda, ação social implica comunicação, implica ao menos a comunicação do significado da ação ou da intenção do ator [...]. E acima de tudo, comunicação não é um tipo de ação porque ela sempre contém um significado muito mais rico do que expressar ou apenas mandar mensagens. [...] A perfeição da comunicação implica a compreensão, e compreensão não é parte da atividade do comunicador e não pode ser atribuída a este. Por isso, a teoria dos sistemas sociais autopoiéticos requer uma revolução conceitual na sociologia: a troca da teoria da ação pela teoria da comunicação como caracterização do nível operativo elementar do sistema. A relação entre ação e comunicação tem de ser revertida (LuHMANN, 1990, p. 06, em livre tradução).
\end{abstract}

Neste contexto, o conceito básico da sociologia se torna o sentido (Sinn). Como complexidade é definida por "a totalidade dos acontecimentos possíveis", se pressupõe aos sistemas sociais um redutor de complexidade fundamental, um mecanismo básico que faça uma pré-seleção das possibilidades. Esse redutor comunicativo é o sentido, que

[...] constitui-se apenas no horizonte do mundo como identidade com referência realizável a outras possibilidades. Sentido é seleção a partir de outras possibilidades; é portanto, ao mesmo tempo, referência $a$ outras possibilidades. O donde da seleção, a complexidade reduzida, permanece preservado no sentido. [...] O sentido serve para a apreensão e redução da complexidade do mundo e, só assim, serve para a orientação da vivência e da ação (LuhmanN, 2005, p. 79).

2 A comunicação "luhmanniana" consiste na síntese de três seleções: Notificação (Mitteilung), Informação (Information) e Compreensão (Verstehen). "Se fala em comunicação quando Ego compreende que Alter notificou uma informação" [Tradução minha de "Man spricht Von Kommunikation, wenn Ego versteht, daß Alter eine Information mitgeteilt hat"] (BARALDI et al, 1997, p. 89). 
Os sistemas sociais também possuem essa função de apreensão e redução da complexidade. "Servem para a mediação entre a extrema complexidade do mundo e a capacidade muito menor, dificilmente alterável por razões antropológicas, do homem para a elaboração consciente da vivência" (Luhmann, 2005, p. 80). A partir da relação desses sistemas com o ambiente, a relação dentro/fora, os sistemas sociais estabelecem suas fronteiras, onde o interno possui sentido, excluindo assim as possibilidades (os possíveis outros sentidos) que ficaram para além dessas fronteiras. Dentro desses sistemas, os indivíduos agem com alguma liberdade, mas essa liberdade está limitada como se houvesse um menu de opções pré-determinadas. Em teoria, se poderia fugir dessas opções pré-selecionadas, mas isso seria como uma pessoa perguntando as horas à outra e esta outra respondendo que o céu está muito bonito. A comunicação não se realiza. Mesmo a pré-seleção realizada pelo sentido não encerra o problema da complexidade. As possibilidades restantes ainda são imensas (na metáfora que acabei de fazer, seria como se o menu ainda fosse muito extenso). Além do mais, há um paradoxo envolvido nesta operação: "a comunicação envolve simultaneamente redução de complexidade (pela seleção) e aumento de complexidade (ao introduzir informação no sistema)" (CoHN, 1998, p. 08). Por isso, um sistema pode ser bem menos complexo do que seu ambiente, mas ainda assim a complexidade dentro dele ser enorme.

Graças à sua complexidade peculiar, um sistema pode, cada vez mais, introduzir em si problemas do ambiente, dar-lhes uma versão diferente, muitas vezes incomparável, e criar assim um marco de referência simplificado para a inserção, consciente ou inconsciente, de técnicas de resolução de problemas internos ao sistema [...]: há diferentes problemas de substituição para a complexidade, na dimensão temporal, sobretudo o problema da existência; na dimensão objetiva, o problema da escassez e, na dimensão social, o problema da dissensão. O mais corrente entre eles é o problema da existência. [...] A questão da existência deve pôr-se sempre num horizonte temporal a limitar e referir-se a um sistema determinado (LuHMann, 2005, p. 85-86).

Em relação às estruturas sociais, a teoria sistêmica de Luhmann é bem mais flexível do que a teoria estrutural-funcionalista. Para Luhmann, esta diferença está no fato de que sua teoria não considera a diferença entre estrutura e processo como o "firme e o fluido", como fazia a teoria parsoniana. Nesta nova teoria "as estruturas são apenas relativamente firmes e também se podem alterar" (LuHMANN, 2005, p. 90). A estrutura é vista ainda como fornecedora de sentido para o complexo 
através de códigos de significações, sendo assim, portanto, seletiva e não apenas diretiva (e diretiva justamente por seu sentido informativo). "Em certo sentido, toda estrutura assenta, pois, na ilusão - na ilusão acerca da verdadeira complexidade do mundo" (Luhmann, 2005, p. 92). Faz-se necessária a distinção entre as estruturas do ambiente, onde a complexidade do mundo é apreendida e reduzida; e as estruturas dos sistemas, que apreendem e reduzem a complexidade dos sistemas.

A análise das estruturas sistêmicas tem, neste contexto, a primazia, porque delas depende que estruturas mundanais serão possíveis para um sistema. Concepções, como a de um tempo objetivo, aberto ao futuro, de um contexto causal do mundo em princípio infinito ou de um ser-sujeito de todos os homens são possíveis só em sociedades bastante complexas, porque evidenciam a dimensão temporal, a dimensão física e a dimensão social como muito complexas. [...] Os sistemas sociais adquirem uma estrutura sistêmica que vai além da situação e definem fronteiras do sistema, mediante a generalização das expectativas para o comportamento peculiar ao sistema (LuHMAnN, 2005, p. 93).

Esta generalização das expectativas é, como será observado mais adiante, uma das principais características da confiança e, como esta (e provavelmente por essa razão), possui a mesma função: a redução da complexidade. Essa generalização determina o comportamento que é normal e o que não o é dentro do sistema, ou seja, do que é possível e o que não é. "Esta escolha prévia do possível no sistema ocorre no plano da expectativa, e não da ação imediata, porque só assim se pode transcender a situação, na antecipação do futuro" (Luhmann, 2005, p. 94). A referência de onde o sistema adquire essas generalizações é obtida fundamentalmente de duas formas: história e organização. A primeira dessas formas - a história recordada - "é, porventura, o meio mais importante, pelo menos um meio indispensável, de redução da complexidade. O passado já não tem mais possibilidades. É complexidade reduzida" (Luhmann, 2005, p. 98). Os indivíduos tomam como referência para as suas ações, as ações passadas, já ratificadas e providas de consenso. Neste sentido, o passado adquire um valor simbólico do que é o correto. A segunda dessas formas de adquirir generalizações é a organização:

[que] sob este ponto de vista, é o equivalente funcional da história, embora nunca a possa substituir. A organização fornece uma generalização congruente de expectativas em virtude de estabelecer o reconhecimento de determinadas expectativas como condição para se ser membro de um sistema. [...] A organi- 
zação pode criar certezas novas, sem história e, de acordo com o famoso dito de Kirchmann, reduzir a lixo, de uma penada, bibliotecas inteiras, mas isto só mediante decisões que se tornam história nos sistemas sociais organizados e nunca se podem alterar de uma só vez (Luhmann, 2005, p. 99).

Para seguir com a redução da complexidade, os sistemas complexos desenvolvem uma diferenciação interna em subsistemas. Cada um destes subsistemas possui suas próprias generalizações de expectativas de comportamento específicas, mas, ao mesmo tempo, todos os subsistemas são interdependentes e frequentemente causam perturbações quando ultrapassam suas fronteiras e penetram em outros subsistemas. Não se esgotam os exemplos da intromissão do sistema econômico no sistema político e vice-versa. Políticos se comunicando através do dinheiro e empresários através do poder político. Devido aos evidentes problemas gerados por essas invasões, "a preservação de uma certa autonomia dos sistemas parciais é uma exigência inevitável das sociedades altamente complexas, e que se deve repetir ainda nos seus sistemas parciais mais complexos” (LuHMANn, 2005, p. 102).

É fundamental entender, principalmente para este trabalho, o processo básico de redução de complexidade, a qual "tem lugar, de modo inevitável, no decurso do tempo mediante o translado do futuro, que ainda está aberto nas suas possibilidades, para o passado imutável" (Luhmann, 2005, p. 105). Para Luhmann, o problema fundamental da sociologia é a complexidade e a consequente tentativa humana de reduzi-la. Com isto em mente, este sociólogo alemão observou como um elemento fundamental do cotidiano humano, a confiança, consiste exatamente em um mecanismo de redução de complexidade.

\section{UM MECANISMO DE REDUÇÃO DA COMPLEXIDADE SOCIAL}

Com a complexidade social como problema fundamental, Luhmann publica, em 1968, o livro Vertrauen: Ein Mechanismus der Reduktion sozialer Komplexität (Confiança: um mecanismo de redução da complexidade social) na tentativa de oferecer uma definição clara do que é o fenômeno da confiança, utilizando sua nascente Systemtheorie como ponto de vista.

Luhmann afirma que "são caos e medo paralisante as únicas alternativas à confiança” (LuHMANn, 200ob, p. 01, em livre tradução). O fator fundamental para o qual se faz necessária a confiança entres os indivíduos é a imprevisibilidade do comportamento dos outros. Esta imprevisibilidade foi conceituada por Parsons e retomada por Luhmann através do teorema da "dupla contingência" (double 
contingency em Parsons; doppelte Kontingenz em Luhmann), conceito necessário para dar conta da possibilidade de interação entre os indivíduos, e da possibilidade da própria ordem social. A consciência desta dupla contingência é uma forma direta de os indivíduos vivenciarem a complexidade social, e por isso se fazem necessários mecanismos que diminuam estas contingências, pré-selecionem as possibilidades de ações dos indivíduos e, consequentemente, reduzam a variedade de comportamentos esperados possíveis. "Através da existência de um alter ego, o ambiente dos seres humanos torna-se o mundo da humanidade" (LuHMANn, 200ob, p. o8, em livre tradução).

Contingência, neste contexto luhmanniano, significa a possibilidade de qualquer seleção dentre as múltiplas possíveis, deixando outras escolhas abertas. Esta contingência não significa dependência mútua, mas a seleção entre diversas alternativas por dois sistemas psíquicos autônomos, num movimento circular que produz indeterminância. É por este processo de dupla contingência que a interação se torna sistema social. Neste ponto, a solução para este problema fundamental da dupla contingência difere entre os dois autores. Para Parsons, a interação seria garantida pelo compartilhamento de normas e valores, numa mesma herança cultural. Havia aí uma certa presunção de consenso, colocando muita ênfase na socialização dos indivíduos. Já em Luhmann, a dupla contingência passa a ser vista como um problema constantemente renovado, em cada interação, o que insere uma instabilidade básica nos sistemas. Para o sociólogo alemão, não há consenso e, portanto, a solução não está nas normas compartilhadas, mas requer comunicação e sua ordenação através da formalização em sistemas e meios de comunicação simbolicamente generalizados. "O sistema regula a insegurança, pois ele [...] estrutura as possibilidades de comunicação” (BARALDI et al, 1997, p. 39, em livre tradução). Esta comunicação acaba, no entanto, por inserir novas contingências e, portanto, nova complexidade à interação. "A condição de dupla contingência inicia comunicação e essa comunicação inevitavelmente constitui um sistema social como uma rede de seleções reciprocamente significativas - o que reproduz o mesmo problema de dupla contingência" (VANDERSTRAETEN, 2002, p. 88, em livre tradução).

\section{CONFIANÇA E TEMPO}

A problemática da confiança possui uma relação direta com o tempo. "Quem demonstra confiança, antecipa o futuro. Ele age como se o futuro para ele fosse mais seguro" (Luhmann, 200ob, p. 09, em livre tradução). Da mesma forma que outros mecanismos de redução da complexidade, alguns já citados em páginas 
anteriores, a confiança utiliza generalizações de comportamentos baseados na experiência prévia do sistema ou do indivíduo. Isso ocorre tanto para influenciar as ações dos indivíduos, quanto para compreender as ações dos outros indivíduos e formar expectativas sobre as possíveis reações destes em relação às ações daqueles. Estas generalizações são jogadas nas expectativas das ações futuras, tentando tornar este futuro esperado em presente real.

O passado já é complexidade reduzida. É evento já realizado, escolha já feita e aceita. Por isso o passado serve como referência para as ações futuras. "Nos mundos confiados, o passado domina o presente e o futuro. No passado, não existem mais 'outras possibilidades"' (Luhmann, 200ob, p. 23, em livre tradução). Através deste processo, essa dimensão temporal da confiança dissolve o problema da ação inesperada, ocultando assim a contingência social. Dessa forma, a constituição de sentidos num mundo confiável torna-se anônima. "A essa forma de constituição anônima correspondem como meios de comunicação a verdade e como estilo notório a familiaridade" (Luhmann, 20oob, p. 21, em livre tradução). Por isso, a confiança só é possível neste mundo familiar. Aquele sistema ou indivíduo que cumpre com os comportamentos esperados, torna-se mais previsível, portanto, mais seguro na vista dos outros, torna-se familiar. Da mesma forma, quem costuma romper com as convenções sociais torna-se "insegurança”, imprevisível. Essa familiaridade é um pressuposto para a confiança e também para a desconfiança, já que o familiar não é necessariamente algo favorável ou desfavorável. "Familiaridade, neste sentido, possibilita expectativas relativamente seguras e com isso também uma absorção de riscos permanecidos” (Luhmann, 200ob, p. 22, em livre tradução). Estas expectativas, como acaba de ser dito, são apenas relativamente seguras. Aí entra uma característica comum em mecanismos de redução da complexidade social: a indiferença. Indiferença em relação às possíveis decepções. Nos processos de redução de complexidade, a complexidade é, de certa forma, ignorada, para que se possa agir como se esta não existisse.

No ato de confiar a complexidade do mundo futuro é reduzida. O agente cheio de confiança se engaja como se no futuro só houvessem algumas determinadas possibilidades. Ele define seu presente futuro num futuro presente. Ele faz aos outros seres humanos a oferta de um determinado futuro em um futuro comum, que não segue se resignando ao passado comum, mas que ao invés disso abrange algo novo. Familiaridade e confiança são, portanto, meios complementares de absorção de complexidade, e, como passado e futuro, atados um ao outro (LuHMANN, 200ob, p. 24, em livre tradução). 


\section{CONFIANÇA E RISCO}

Um elemento fundamental da confiança é que ela pressupõe risco. De acordo com Luhmann, "cada vez mais situações perigosas são consideradas não, como em formas societais antigas, como o resultado da natureza, de Deus ou do destino, mas como o resultado de decisões" (Luhmann apud Holmström, 2007, p. 258, em livre tradução), as quais impõem ao sujeito que decide responsabilidade pelas possíveis consequências. Uma ação baseada na confiança tem de ter a possibilidade da ruptura da confiança maior do que as vantagens obtidas através dela. Sem esse risco, torna-se apenas esperança. "Confiança reflete contingência, esperança elimina contingência” (Luhmann, 200ob, p. 29, em livre tradução). A confiança tem de poder ser "enganada", nunca são oferecidas informações suficientes para se agir com total segurança. Confiança é, "como percebeu Simmel, uma mistura de saber e não saber" (Luhmann, 200ob, p. 31, em livre tradução). Por essa razão, Luhmann percebe que, no processo de confiança, muitas informações são encobertas.

O mundo objetivo possui uma complexidade muito maior do que o sistema; ele abarca mais possibilidades [...]. O sistema interpreta o mundo de forma seletiva, encobre a informação que ele recebe, reduz a complexidade externa do mundo em um perímetro onde ele possa orientar-se com significado, ganhando assim possibilidades estruturadas de experiências e comportamentos próprios. A redução pode ocorrer intersubjetivamente e segue assim para um conhecimento, que é socialmente garantido e, portanto, vivenciado como "verdadeiro". Nesses casos o sistema substitui informações externas por informações internas, por exemplo, por premissas estruturadoras do próprio processamento das experiências que ele já aprendeu. (LuHMAnN, 200ob, p. 39, em livre tradução).

A inteligência humana seleciona as informações aparentemente mais relevantes e as reinterpreta da maneira que lhes conferirá sentido. Este processo deixa várias lacunas na compreensão da experiência, que são preenchidas por elementos estruturais abstratos, dando uma aparência mais segura à existência. Através desses elementos, o sistema posterga decisões, ganhando tempo e possibilitando a ação imediata. Dessa forma, mesmo sem informações concretas anteriores ao momento onde a confiança aparece como necessária, se pode confiar. Por essa razão, Luhmann escreve que "confiança é informação encoberta, consiste em que o confiador, em certos contornos, já sabe, já está informado, mesmo quando não possui densidade suficiente, não completamente, não fiável” (LuHMANN, 200ob, p. 40, em livre tradução). 
Em sociedades mais simples, nas quais as pessoas se conhecem umas as outras em uma medida muito maior do que nas sociedades complexas, a confiança aparece como norma e a desconfiança como transgressão à boa vivência social. Nestes casos, confiança e justiça não se separam. "O desconfiado, sob tais circunstâncias, não pode dar expressão aos seus sentimentos e apreensões, sem se isolar socialmente" (LuHmann, 200ob, p. 42, em livre tradução). Já nas sociedades modernas complexas, a separação entre confiança e justiça é inevitável e, portanto, os riscos são individualizados. Não existe decisão livre de riscos, além do que, "no mundo moderno não decidir é, claro, também uma decisão" (Luhmann, 1993, p. 27, em livre tradução). Neste sentido, as garantias mais concretas, que dão um ar de proteção à situação na qual o indivíduo que confia se encontra, jazem na ideia de que o indivíduo, objeto da confiança, deseje, por qualquer razão, o prolongamento do relacionamento e, portanto, tema as sanções implícitas para a ocasião em que este deseje quebrar a confiança daquele. Algo esclarecedor desta situação é o exemplo utilizado por Russell Hardin (2004) quando trata da confiança como interesse encapsulado. Hardin usa um momento da obra "Os Irmãos Karamazov" do escritor russo Fiódor Dostoiévski, no qual o personagem Dmitry Karamazov conta a história de um tenente coronel que se envolve em um esquema de corrupção com um mercador chamado Trifonov. O tenente coronel emprestava uma soma substancial do dinheiro administrado por ele à Trifonov, e este retornava com a quantia mais o lucro, retirada, naturalmente, sua parte. Hardin nos conta que enquanto o relacionamento seguia com ambos lucrando, o tenente coronel podia confiar tranquilamente em Trifonov, e este nele (HARDIN, 2004, p. 02). Certo momento, o tenente coronel foi substituído do seu comando. Logo em seguida, pediu para Trifonov o retorno das 4500 rublas que tinha lhe emprestado, recebendo uma negativa deste, já que tal "negócio" nunca havia existido. A ideia de Hardin, que se liga a esta de Luhmann, é que a confiança entre estes dois homens só se mantinha pelo desejo de ambos em continuar com o relacionamento. Naturalmente, essa ideia da garantia de um ambiente de confiabilidade através da duração dos relacionamentos pode e deve ser estendida ao sistema social inteiro. De acordo com Luhmann,

[...] em contextos sociais que são estruturados dessa maneira, a saber, através da otimização da relativa duração dos relacionamentos, dependência mútua e um momento de imprevisibilidade, se encontra um solo fértil favorável aos relacionamentos de confiança. Aí domina a lei do reencontro. Os participantes devem sempre poder se olhar nos olhos novamente (LuHMANn, 200ob, p. 46, em livre tradução). 


\section{CONFIANÇA E LIBERDADE}

Para o desenvolvimento dos relacionamentos pessoais de confiança é exigido, primeiramente, que as ações sejam vistas como pessoais (LuHmann, 2000b, p. 51). Para serem vistas como pessoais, os sujeitos das ações têm de ter liberdade para agir. A liberdade de ação dos indivíduos é o que torna a vida social ainda mais contingente, por consequência, mais complexa. É a clássica ideia da preocupação com a imprevisibilidade das ações dos outros indivíduos. O próprio Luhmann comenta que esta imprevisibilidade, quando foi analisada por Thomas Hobbes, se observou como uma solução para o problema da figura do Estado autoritário, o Leviatã. (Luhmann, 200ob, p. 07). Com isto em mente, podemos compreender as experiências fracassadas do fascismo, do comunismo e do corrompimento da confiança nos países que sofreram sob estes regimes que cortaram a liberdade dos indivíduos e tentaram eliminar essa imprevisibilidade dos comportamentos e ações. Particularmente no caso do leste europeu, como demonstra Piotr Sztompka na sua obra "Trust: A Sociological Theory" (1999), a "cultura de bloco" uniformizante teve como efeito a extrema desconfiança no público e a confiança cega na esfera privada. Estes exemplos evidenciam a ligação entre liberdade e confiança. Liberdade esta que traz responsabilidade. Responsabilidade das pessoas sobre as suas escolhas, sobre os seus atos. Liberdade que transforma a ação em ação pessoal, "a qual se arca pessoalmente com a responsabilidade" (LuHMANn, 200ob, p. 51, em livre tradução).

Vimos acima que um indivíduo ou sistema é familiar se seu comportamento for o comportamento aceito como tendo sentido. Disto, Luhmann percebe algo que Simmel (1992) também havia percebido: "que o estranho não confiável goza de mais liberdade e pode agir mais desprevenido" (Luhmann, 200ob, p. 82, em livre tradução), pois, por já não estar sendo digno de confiança, não necessita manter as convenções. Um indivíduo permanece como confiável quando mantém ao mesmo tempo sua auto-representação (Selbstdarstellung) como familiar. Neste sentido, um indivíduo poderia até ganhar confiança através de uma auto-representação falsa, mas ele só pode manter esta confiança se mantém também essa representação. "Confiança se acumula como uma espécie de capital que abre mais possibilidades às ações de maior alcance, mas também deve ser utilizada e cuidada continuamente" (LuHMAnN, 200ob, p. 84, em livre tradução). Dessa forma, nessa submissão às condições de confiança, o indivíduo ou sistema mostra que busca ganhar confiança.

Isto se refere não mais a que o outro permaneça o que é, mas que ele continue com sua auto-representação e se sinta conectado pela história da sua auto-repre- 
sentação. Na medida em que essa reflexividade se torne consciente, também se tornará a confiança pessoal uma variante da confiança sistêmica. [...] Apenas essa forma da confiança pode tornar consciente a função da confiança, a função da redução de complexidade frente à liberdade dos outros seres humanos, e assim encontrar uma orientação. [...] O alicerce de toda confiança é a representação do seu próprio self como uma identidade social, construída em interações e correspondente ao ambiente (LuHMANN, 200ob, p. 80, em livre tradução).

Luhmann faz o alerta de que isso não significa de forma alguma um conformismo. O conformismo de papéis, ao contrário, não oferece muita ocasião a essa auto-representação. Para ser visto como um self é preciso aceitar expectativas estranhas, não simplesmente se adaptar.

\section{CONFIANÇA, REFLEXÃO E DESCONFIANÇA}

As ordens sociais complexas exigem que os mecanismos cognitivos dos indivíduos se tornem mais reflexivos. Estes mecanismos reflexivos, quando se institucionalizam, aumentam o potencial de complexidade que essa ordem social pode suportar. "Enquanto na confiança pessoal reflexividade é um fenômeno excepcional, a confiança sistêmica ergue-se em cima de que os outros também confiem e que essa comunhão de confiança se torne consciente. [...] A base racional da confiança sistêmica está na confiança do outro" (Luhmann, 200ob, p. 92, em livre tradução).

É fundamental entender que confiança e desconfiança são dois lados da mesma moeda. São equivalentes funcionais, e, portanto, se deve escolher entre um ou outro. Ambos reduzem a complexidade social, só que enquanto a confiança o faz mirando expectativas positivas no seu objeto, a desconfiança observa essas expectativas como negativas. Enquanto a confiança induz a cooperação entre os indivíduos, a desconfiança torna o seu objeto algo ruim, algo a ser combatido. Por essa razão, por essa cautela com o inimigo, a desconfiança perde frequentemente sua consciência, tornando-se rotina, principalmente nas relações impessoais. Dessa forma, a desconfiança produz simplificações, pois se torna fortemente dependente de apenas poucas informações. "Expectativas negativas são muito complexas para a desconfiança, pois elas pouco excluem. [...] Confiança, por outro lado, é psicologicamente o caminho mais leve" (LuHMANn, 200ob, p. 94, em livre tradução). Nas relações pessoais, a desconfiança é transformada em comportamento desconfiado. O desconfiado pode desejar mostrar sua insatisfação, se deseja que o relacionamento continue. O objeto dessa desconfiança normalmente se recusa a observar 
em si as causas dessa atitude e geralmente responde também com desconfiança. "A desconfiança tem, pois, uma tendência inerente de se ratificar e fortalecer na relação social - [...] [tendência] a qual Merton, sob a designação 'self-fulfilling prophecy', dedicou um clássico ensaio" (LuHmann, 200ob, p. 98, em livre tradução).

\section{A DISPONIBILIDADE E A RACIONALIDADE DA CONFIANÇA}

Para estar preparado para receber confiança, um sistema ou um indivíduo necessita dispor de segurança interna. "Logo, o problema da disposição para confiança consiste não de um acréscimo de segurança sob diminuição adequada de insegurança; ele está, ao contrário, em um acréscimo de insegurança sustentável ao custo de segurança" (Luhmann, 200ob, p. 104, em livre tradução). Uma forma de garantir essa disposição está em outro elemento de redução de complexidade: o afeto sentimental a determinados objetos ou pessoas. Um exemplo fundamental disso é a forma básica de aprendizado sobre a confiança em todos os seres humanos, a fixação sentimental do bebê em relação aos pais. A necessidade humana de se apegar a outros torna o sentimento uma base para relacionamentos de confiança, mesmo quando o sentimento não está exatamente presente. Outra forma de disposição para confiar está na própria autoconfiança do indivíduo em relação à sua auto-representação como alguém confiável. "Quem confia se representa como alguém cujo Ser está disposto a presentear confiança”" (LuHMAnN, 200ob, p. 109, em livre tradução). Em todos os casos, esta disponibilidade depende muito também de fatores estruturais do sistema, algo como a cultura da confiança da teoria de Piotr Sztompka (1999).

No final da sua obra sobre a confiança, Luhmann tenta esclarecer a racionalidade desta. Confiança, de acordo com ele, não é um meio escolhido para um determinado fim. Não se insere em um modelo de cálculo meio/fim. Esses modelos de cálculo são, na verdade, equivalentes funcionais da confiança, já que estes também pretendem reduzir a complexidade social. Mas sob o ponto de vista da sua função de redutora de complexidade, a confiança é racional. Sem ela, apenas formas simples de cooperação humana seriam possíveis, se alguma sequer fosse. A confiança aumenta o potencial de ação de um sistema social. "Através da confiança, um sistema ganha tempo, e tempo é a variável crítica na construção de estruturas sistêmicas mais complexas" (Luhmann, 200ob, p. 117). Da mesma forma, é racional a desconfiança como proteção frente à uma insegurança muito grande. A confiança é bem mais rapidamente transformada em insegurança do que o contrário. Daí a analogia ética que diz que "a confiança deve ser a regra e 
a desconfiança a exceção, que na dúvida a confiança ganhe a preferência, mas deixando espaço para a desconfiança” (Luhmann, 200ob, p. 119, em livre tradução).

\section{CONCLUSÃO}

Na obra de Luhmann observei como a confiança está ligada ao problema fundamental da existência humana, que, por sua vez, também é um problema fundamental da sociologia: a complexidade. A extrema complexidade frente à limitada capacidade do conhecimento humano nos faz desenvolver mecanismos para podermos tolerar esta contingência, para assim podermos agir e exercitar nosso desejo de viver. A confiança se manifesta sob diversas formas na vida humana: ela pode estar presente tanto nas nossas relações mais íntimas quanto nas nossas relações com figuras abstratas como as instituições e organizações sociais. Ela traz o passado bem-sucedido para as expectativas de um futuro mais seguro, menos complexo, fazendo, normalmente, com que esta profecia se auto-realize, mas tendo sempre presente a possibilidade de que o contrário ocorra. Colocamos cobertas nas contingências para não as enxergar e dessa forma podermos agir com menos receio. Se isto não for possível, invertemos os pólos e mostramos toda nossa insatisfação através da desconfiança.

A confiança é como a dádiva, ela não pode ser exigida, ela é oferecida e, depois de aceita, exige que seja respeitada, preservada e retransmitida. A confiança é racional, à sua maneira, como é racional a ideia de que se todos formos confiáveis, sem o intermédio de entes superiores tentando forçar a retirada da contingência, nossa existência se tornará mais prazerosa, pois nosso leque de possibilidades de ação será maior, sem que com isto limitemos as ações dos outros.

\section{REFERÊNCIAS BIBLIOGRÁFICAS}

BARALDI, Claudio; CORSI, Giancarlo; ESPOSITo, Elena. GLU : Glossar zu Niklas Luhmanns Theorie sozialer Systeme. Frankfurt am Main: Suhrkamp, 1997.

Cohn, Gabriel. As diferenças finas: de Simmel a Luhmann. Rev. bras. Ci. Soc., São Paulo, v. 13, n. 38, 1998. <http://www.scielo.br/scielo.php?script=sci_arttext\&pid=So10269091998000300003\&lng=en\&nrm=iso >

GambetTA, Diego (org.). Trust: Making and Breaking Cooperative Relations. Oxford: Basil Blackwell, 1988.

Hardin, Russell. Trust. Cambridge: Polity Press, 2006.

Hardin, Russell. Trust and Trustworthiness. New York: Russell Sage Foundation, 2004. Holmström, Susanne. Niklas Luhmann: “Contingency, risk, trust and reflection”. Public Relations Review, Vol. 33: 255-262, 2007. 
Luhmann, Niklas. Essays on Self-Reference. New York: Columbia University Press, 1990. Luhmann, Niklas. “Familiarity, Confidence, Trust: Problems and Alternatives”. In: GambetTA, Diego (org.) Trust: Making and Breaking Cooperative Relations. Oxford: Basil Blackwell: 94-107, 2000a.

Luhmann, Niklas. "Sociologia como teoria dos sistemas sociais". In: SAntos, José Manuel (org). O pensamento de Niklas Luhmann. Universidade da Beira Interior, 2005

Luhmann, Niklas. Soziale Systeme: Grundriß einer allgemeinen Theorie. Frankfurt am Main: Suhrkamp, 1994.

Luhmann, Niklas. Risk: A Sociological Theory. Berlin \& New York: Walter de Gruyter, 1993. Luhmann, Niklas. Vertrauen: ein Mechanismus der Reduktion sozialer Komplexität. Stuttgart: Lucius und Lucius, 200ob.

SAntos, José Manuel (org). O pensamento de Niklas Luhmann. Universidade da Beira Interior, 2005.

Simmel, Georg. Soziologie: Untersuchungen über die Formen der Vergesellschaftung. Frankfurt am Main: Suhrkamp, 1992.

SztompкA, Piotr. Trust: A Sociological Theory. Cambridge: Cambridge University Press, 1999.

Sztompкa, Piotr. “Trust, Distrust and Two Paradoxes of Democracy”. European Journal of Social Theory, v. 1, n. 1,p. 19-32, 1998.

VAnderstraeten, Raf. Parsons, Luhmann and the Theorem of Double Contingency. Journal of Classical Sociology, Vol. 2 (1), p. 77-92, 2002.

Recebido para publicação em: 29/03/2016. Aceito para publicação em: 22/08/2016. 